\title{
What is the How: Participatory Sense-making as Consensual Validation of Phenomenal Data
}

\author{
Aleš Oblak ${ }^{1}$ \\ ${ }^{1}$ University of Ljubljana \\ Centre for Cognitive Science \\ Ljubljana, Slovenia
}

\begin{abstract}
We propose a method of consensually validating phenomenal data. We believe such a method is necessary due to underreporting of explicit validation procedures in empirical phenomenological literature. We argue that descriptive science, exemplified by phenomenology and natural history, rely on nominalization for construction of intersubjectively accessible knowledge. We compare the epistemologies of phenomenology and natural history, pointing out that they differ in their attitudes towards the interpretation of texts and visual epistemology, however, they both rely on eidetic intuition of experts for knowledge construction. In developing our method, we started out with the prismatic approach, a method of researching embodied social dynamics. We then used debriefings on the experience of consensual validation to further refine the method. Importantly, we suggest that for a nominalization of experiential world to be intersubjectively accessible, a group of co-researchers has to independently construct said vocabulary. We therefore propose that during consensual validation, co-researchers be presented with composite descriptions of experiential categories, compare them with their experience, attempt to falsify them, and finally jointly name them. Our approach does not yield a single vocabulary for description of experience, but a number of commensurable vocabularies, contingent on a specific research setting.
\end{abstract}

\section{KEY WORDS}

consensual validation, phenomenal data, participatory sense-making, empirical phenomenology, intersubjective accessibility

\section{CLASSIFICATION}

APA: 2260 Research Methods \& Experimental Design; 2630 Philosophy, 


\section{INTRODUCTION}

In this paper, we present a method of consensual validation of phenomenal data. In qualitative research, consensual validation refers to the process of checking with our coresearcher whether the categories obtained during the analysis of raw data correspond to their experience [1]. We propose to make use of participatory sense-making to establish intersubjective vocabulary to describe specific aspects of our co-researchers' ${ }^{1}$ experience. We understand phenomenal data to be consensually validated when a group of co-researchers possesses a vocabulary with which they can describe their experience.

Our method constitutes a fusion of the prismatic approach and participatory sense-making, supported by theoretical discussions. We started with the prismatic approach, a method for the study of embodied social dynamics and based on our co-researchers' feedback, we iteratively adjust it to our purposes.

This paper has two aims. The first is to offer a method of validating phenomenal data as the term is understood by Varela and Shear [2]. While consensual validation has been claimed in various studies [3, 4], a detailed protocol has thus far not been described. In light of scientific transparency [5], in particular when it comes to qualitative research, [6] we believe that explicit protocols for consensual validation are necessary.

Our second aim is to provide a way for phenomenal data to be operationalized. We hold that only if aspects of experience investigated in a given study are intersubjectively accessible, we can treat them as theoretical constructs. This, in turn, would allow a group of co-researchers to engage in neurophenomenological studies [7], whereby the newly developed theoretical constructs could be operationalized as experimental variables [8].

The paper is structured as follows: In the first section, we draw a comparison between phenomenology and natural history as exemplars of descriptive sciences, arguing that nominalization in both of them constitutes intersubjectively accessible data to support our position that only such data can be operationalized. In the second section, we argue that any vocabulary with which we might refer to shared experience needs to be autonomously constructed. In the third section, we present how we developed our method. In the fourth section, we present our guidelines for consensual validation of phenomenal data. In the fifth section, we discuss the epistemic status of phenomenal data validated with our approach.

\section{CONSENSUAL VALIDATION AS INTERSUBJECTIVE ACCESSIBILITY: THE CASE OF PHENOMENOLOGY AND NATURAL HISTORY}

In this section, we discuss the nature of intersubjectively valid data, particularly in the context of descriptive science. What for many researchers precludes the scientific study of experience is the claim that phenomenal data is subjective i.e., that experiential reports are inaccessible to a community of researchers and thereby cannot constitute objects of scientific inquiry. Namely, two researchers cannot observe phenomenal data as it is only accessible in the first person. We argue, however, that through nominalization ${ }^{2}$ we can make phenomenal data asymptotically approach the point where the overlap between experiences of different individuals is considerable enough to denote an intersubjectively accessible phenomenon. Intersubjective accessibility would make phenomenal data accessible to a community of researchers (i.e., they would be in agreement regarding the object of investigation). This approach is valid within natural history. By analogy, we believe that this holds in descriptive 
sciences across the board, including phenomenology. Phenomenal data, however, can only approach intersubjective accessible on the condition that the nominalization is done in a systematic manner.

We will use the example of natural history to show that descriptive sciences primarily rely on nominalization, i.e., naming of phenomena under investigation, to establish intersubjective consensus about what they are studying.

A common argument leveled against the scientific study of experience is that such a project can be merely descriptive. The derision of descriptive science has been argued to be more of a prejudice $[9,10]$. Biology and astronomy were both descriptive sciences [e.g., 11, 12]; today, calls have been made to return descriptive work into the purview of biological sciences $[13,14]$; and the descriptive approaches have become the gold standard in genetics [15]. A broader defense of descriptive sciences is beyond the scope of this paper. We merely wish to suggest that many scientific disciplines take as the starting point a descriptive project prior to engaging with the construction of predictive models.

We will now argue for descriptive sciences using nominaliziation as a method of rendering their objects of investigation intersubjectively accessible. An example of a descriptive science is biology, specifically when it assumed the form of natural history. Natural history refers to the Modern Era scientific program that aimed at establishing a taxonomy of the natural world. As Michel Foucault [16; p. 114) writes in The Order of Things, "natural history is nothing more than the nomination of the visible." In explanation, $18^{\text {th }}$ century naturalists relied on visual epistemology to investigate the natural world; i.e., the idea that depictions in and of themselves carry epistemic value. Namely, scientists were trained in how to observe, represent, and describe the natural world. That is, the descriptions and depictions provided by experts, trained in scientific observation of the world, were ascribed a truth value. Expert descriptions of plant-life necessitated a philological approach towards the construction of knowledge; i.e., the comparison of different reports had to be conducted both at the level of observation (either of actual preserved specimens or detailed illustration) and the careful study of botanical texts. One could argue that natural history is no longer an accepted scientific program. Note, however, that genetics still constitutes a descriptive science [15].

We argue that there is significant similarity between the methods of natural history and phenomenology $y^{3}$. Much like how observation, description, comparison, and classification constituted the method of natural history (e.g., the Linnaean taxonomy of organisms [17]), phenomenology aims at classifying experience. The centrality of classification in phenomenology is summarized by Jean-Paul Sartre [18; p. 5] in his account of imagination, The Imaginary: "produce images in ourselves, reflect on these images, describe them, which is to say, try to determine and classify their distinctive characteristics."

The taxonomic streak in Sartre is self-evident; however, an important difference between phenomenology and natural history lies in the epistemic value of philology and visual epistemology. The central method of philology, i.e. the exegesis of texts, is criticized heavily by phenomenologist Paul Ricoeur [19; p. 91].

[A]ll interpretation places the interpreter in medias res and never at the beginning nor at the end. We happen upon a conversation which has already begun and in which we try to orient ourselves in order to make our own contribution to it. But the ideal of an intuitive foundation is that of an interpretation which, at a certain moment, would become a total vision.

In other words, the philological method relies solely on the interpretation of texts for the construction of knowledge, while Husserlian phenomenology relies on an intuitive 
understanding of the subject at hand as well (although see also [20]). Similarly, visual epistemology is somewhat problematic in phenomenology. Edmund Husserl's schematized depictions of time consciousness [21], for instance, were criticized and later on amended both by Maurice Merleau-Ponty [22] and Francisco Varela [23]. We argue that this controversial status of visual depictions of experience stems from loss of intuitive information about the subjective dimension of the mind when reducing phenomenal data to merely the visual modality.

Now, to move from the divergences between the epistemologoies of natural history and phenomenology back to their similarities. The biggest commonality between phenomenology and natural history is that they rely on a specific context of observation to achieve an understanding of their respective objects of inquiry. While knowledge construction is supplemented by texts, the principal way in which naturalist obtained knowledge was through the eidetic, i.e. knowledge-giving, intuition of vision. In Visible Empire, a monograph on $18^{\text {th }}$ century botany, Daniela Bleichmar [24; p. 47] writes that naturalists posited two ways of observing the world: the spectacular gaze and the scientific gaze, where

[t]he word "spectacle" does not connote superficial entertainment: while amusing and pleasurable, nature is always instructive. [...] [T] he word "spectacle" refers to a mode of seeing predicated on notions of transparency and immediacy, a way of looking that was open to everyone, regardless of background, and required no specialized training.

By contrast, scientific observation consisted of uncovering the underlying order of nature. Its "goal was not simple, immediate looking but rather expert observation, going beyond superficial traits to focus on the significant (ibid.)." The importance of specialized observation is the biggest difference between natural history and philology proper. Specifically, natural history never relied on texts as the sole source of knowledge [25]. As Bleichmar [24; p. 46] writes: "Eighteenth-century natural history publications repeatedly proclaim that vision constitutes the best method for investigating nature and that images provide the preferred means of transmitting this knowledge. "It is the eidetic intuition of vision that is the true bearer of knowledge in natural history rather than the texts themselves.

Phenomenology relies on a specialized form of observation as well: it observes experience while bracketing [An. Gr. epoché; Ger. Einklammerung] the natural attitude. The idea of the natural attitude is that before reflecting on it, we exist immersed in a world that quite simply appears to be there and we are uncovering it with our senses. Our understanding of the world, of the entities that inhabit it, and of our own consciousness, is laden with assumptions and theories. As Edmund Husserl [26; p. 2] writes in Thing and Space:

In the natural attitude of spirit, an existing world stands before our eyes, a world that extends infinitely in space that now is, previously was, and in the future will be. This world consists of an inexhaustible abundance of things, which now endure and now change, combine with one another and then again separate, exercise effects on one another and then undergo them.

However, if we are to form a truly scientific theory of experience [27 - 30], we must learn how to separate ourselves from the natural attitude. We can do this by performing the act of bracketing. Bracketing refers to suspending the assumptions and theories we hold about the mind, experience, the world and our existence in the world, including scientific theories about it [31]. It refers to an attitude of wonder before the world [32].

We must note that the spectacular gaze and the scientific gaze do not map onto the natural attitude and the act of bracketing, respectively. Instead, both the spectacular gaze and the scientific gaze exist within the natural attitude. Indeed in his preface to the French translation 
of Husserl's [33; p. xx] Ideas Pertaining to a Pure Phenomenology and Phenomenological Philosophy, Ricouer places the whole of natural history within the domain of the natural attitude:

I am at first lost and forgotten in the world, lost among things, in ideas, among plants and beasts, among others [...] We understand Naturalism as the lowest degree of the natural attitude and at this level it conveys its own collapse; because if I am lost in the world, I am already ready to treat myself as a thing in the world. ${ }^{4}$

However, we still believe that the approach of natural history may guide us in constructing consensually validated phenomenal data. Specifically, if naturalism represents a way of nominalizing the visual world as seen by expert observation, phenomenology may be the way of nominalizing the experiential world. And we hold that when nominalization of the experiential is done in a systematic way, it is rendered intersubjectively accessible.

The question, however, is how can we establish a vocabulary that would refer to specific aspects of experience?

\section{PARTICIPATORY SENSE-MAKING AND AUTONOMOUS NEGOTIATION OF MEANING}

The idea of establishing an intersubjectively accessible vocabulary with which to refer to the same aspects of a given experience is not new. For example, during Heinrich Klüver's research into the structure of hallucinations, he discovered that his participants were prone to giving mystical descriptions of their experience. To circumvent this problem, he trained his participants beforehand by providing them with concepts with which to describe their experience. [34]

Further, the idea of naming a specific aspect of one's experience is part and parcel of the qualitative approach to research, where the basic analytical tool is coding. We ascribe abstract descriptions to qualitative reports (typically rendered in the form of text). At the highest levels of abstraction, we may induce categories that are nothing more than words or phrases [35].

However, it is typically the researchers who name the categories under investigation and present them to their participants in order for them to validate the coding process ${ }^{5}$. From our point of view, this approach is problematic as what is established is not a vocabulary which could then be organically used to describe aspects of experience.

Research has shown that if we wish to create a lexicon within which the meaning is grounded in the outside world, the lexemes have to be autonomously constructed and negotiated by different agents [36]. Luc Steels attempted to solve the symbol grounding problem - how symbolic structures relate to the outside world [37] - by constructing artificial agents which at any time could assume control over one of two cameras placed in front of a board of colored shapes. When two agents took control over the cameras, they could point to the same shape and name it. If one of the agents already had a name for the shape and the other one did not, the latter simply adopted the name. If both agents already had a name for it, they negotiated a new name for the shape. Eventually, the community of artificial agents negotiated a shared vocabulary for all of the shapes on board [36]. Steels argues that an autonomous negotiating of meaning is a necessary condition for relating a symbolic structure to an object in an outside word (i.e., for grounding a symbol). 
By analogy with the symbol grounding problem, the question for phenomenology is how we create a vocabulary to describe the experienced world. How can we then go about solving the problem of the construction of a vocabulary with which we would be able to refer to those aspects of our experiential world that are brought to the fore by a specific research situation? One possible approach was suggested by Hanne de Jaegher [38], and Elizaveta Solomonova and Sha Xin Wei [39]: participatory sense-making.

Participatory sense-making refers to an enactivist theory of social cognition and language. The idea behind participatory sense-making is that within social interaction, cognizers coordinate their behaviors such that the social interaction itself becomes autonomous. By constraining each other, the cognizers are then forced to modify their behavior (either bodily or linguistically) so as not to bring the interaction to a close [40, 41]. In the development of our method, we took the position of participatory sense-making seriously. We incorporated it both as a means of validating data (as will be explained below, our co-researchers have to agree on the framework of nominalization), as well as a criterion for validated data (i.e. our vocabulary needs to be conducive to establishing an autonomous interaction).

These theoretical discussions lead to an important methodological consideration within our approach: we do not present our co-researchers with already formed experiential categories (although we may have constructed them during the analysis of phenomenal data). Instead, we provide them with ethnographic descriptions of experience, constructed from a number of reports. During the validation sessions, the community of co-researchers then collectively ascribes names to these descriptions, or - if the descriptions do not correspond to their experience - either divide them further or group them together. In doing so, we further equalize the participant-researcher power dynamics: We invite our co-researchers to be part of the analysis process rather than merely the acquisition process.

This autonomous, collective construction of a vocabulary with which to refer to the coresearchers' experience constitutes the central innovation of our approach. Further, it represents the central criterion for whether we have managed to establish a vocabulary with which to describe our experience: if, by the end of the validation session, the co-researchers are able to discuss their experience naturally with our vocabulary without their interaction breaking down, we consider our phenomenal data consensually validated. This principle is illustrated in Figure 1.

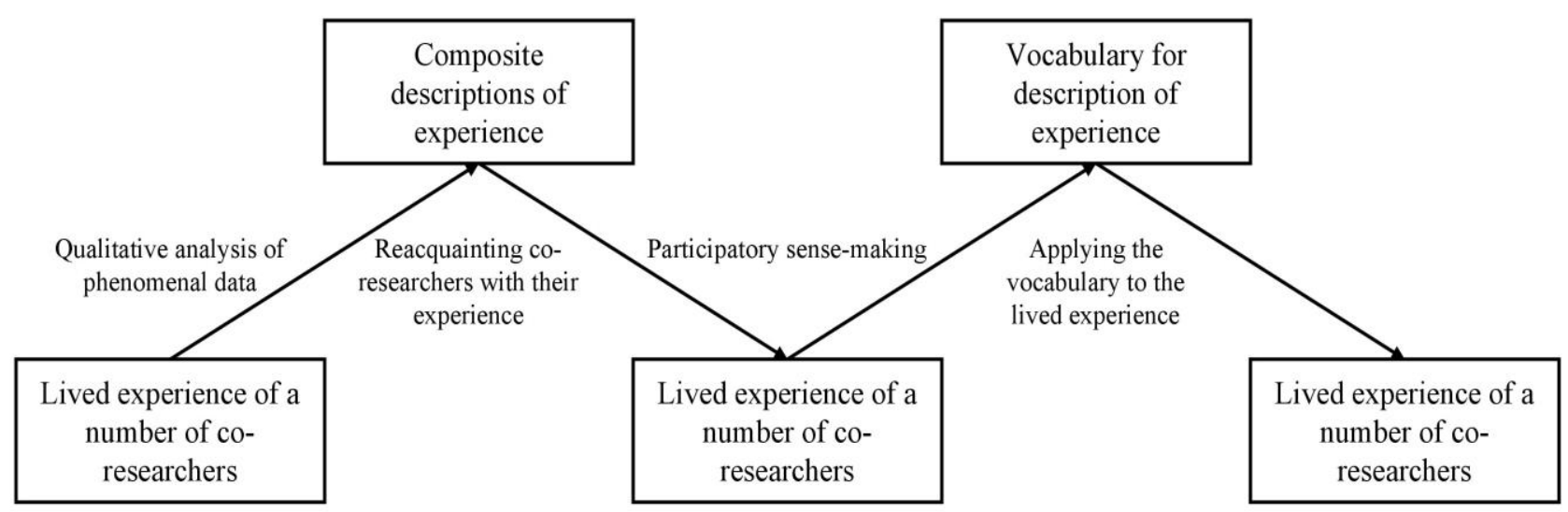

Figure 1: A schematic depiction of using participatory sense-making for consensually validating phenomenal data 


\section{CONSTRUCTING A METHOD OF CONSENSUAL VALIDATION}

In this section, we will present how we constructed our method of intersubjectively validating phenomenal data. We first present our starting point: the so-called prismatic approach. Then, we will present how we augmented this approach using participatory sense-making and philosophical phenomenology. Finally, we will discuss how we used the debriefings on individuals' experience of validating phenomenal data to further improve our method.

The prismatic approach to gathering data on embodied social dynamics was developed by Barbara Pieper and Daniel Clénin [43]. According to this approach, the participants of a given study attend a workshop whose goal is to investigate a specific aspect of their experience. At this workshop, the participants engage in the specific embodied social dynamics that is being investigated by jointly performing a given practice and observing how the related social dynamics unfold. In particular, they are interested in various ways this social dynamics may or may not manifest itself.

From this workshop model suggested by the prismatic approach, we adopted

I. The joint investigation of experience;

II. Reacquainting participants with the aspect of experience under investigation; and

III. Observing different ways in which a given aspect of experience may appear to individuals.

In line with the ideas of reflective cognitive science [43], in particular when it comes to the scientific investigation of experience [44], we conducted debriefings on the experience of validating the data. As a number of critical points entered our co-researchers awareness, we set out to iteratively refine our approach.

Our method was developed alongside a longitudinal empirical phenomenological project that investigated the experience of solving a visual span task [45]. We will briefly outline the research design of the project.

The visual span task consisted of a presentation of a grid, in which certain cells were filled in. The grid was presented for 2500 milliseconds. Immediately after the grid disappeared, an empty grid appeared, and our co-researchers had to fill in the black cells to match the first grid. If the co-researchers successfully reconstructed the grid, they received positive feedback, and the difficulty of the task increased. Conversely, if the co-researchers were unsuccessful in reconstructing the grid, they received negative feedback. Upon making two subsequent mistakes, the task stopped and the co-researchers received a number denoting the span of their visual working memory. Figure 2 depicts an example of a to-be remembered grid. After conducting phenomenological interviews on the experience of solving the visual span task, we analyzed the data according to the principles of constructivist grounded theory [35]. 


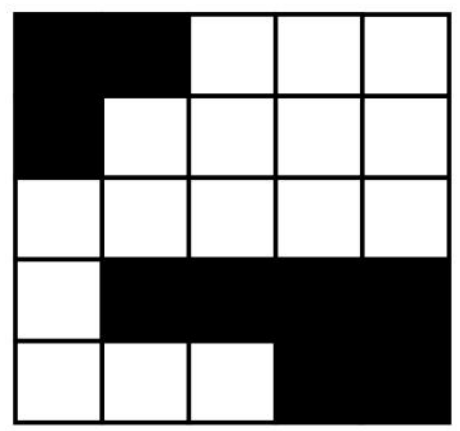

Figure 2: Example of a stimulus in the visual span task

Once we have analyzed our phenomenal data, we conducted consensual validation workshops. We performed consensual validation in order to a) validate our analysis protocol; and b) establish an intersubjective vocabulary with which to refer to different aspects of experience of solving a visual span task (that could be operationalized in an experimental research design).

In total, 18 co-researchers participated in these workshops. After the validation session, the co-researchers were given the following semi-structured questionnaire to report on their experience of the validation session itself:

I. Do you believe we succeeded in establishing a common language to describe the experience of solving a visual working memory task?

II. Do you believe that the group setting changed your experience or your reporting on the experience?

III. Do you believe that aspects of experience that you reported on during the group discussion represent your experience during the performance of the visual working memory task?

IV. Do you believe that having to report on your experience in language changed your experience?

V. What do you think could be changed in our approach to consensual validation?

In the next section, we present our guidelines towards consensually validating phenomenal data.

\section{PARTICIPATORY SENSE-MAKING AS A METHOD OF VALIDATING PHENOMENAL DATA: OUR GUIDELINES}

Based on the theoretical principles outlined in the first two sections, and the feedback gained from our workshops, we reached the following guidelines towards using participatory sensemaking as a method of consensually validating phenomenal data.

I. Our starting point are not categories constructed during the qualitative analysis of the data, but composite ethnographic descriptions; 
II. We provoke the experience during the validation session;

III. Co-researchers are asked to observe whether it is necessary that their experience corresponds to the composite descriptions or whether it can deviate;

Is. Co-researchers collectively construct the vocabulary with which to refer to their experience;

ऽ. The co-researchers once again observe their experience (if that is possible), and describe it with the newly-established vocabulary.

In this section, we will take a closer look at each of these steps, providing principled and empirical support for them.

\section{COMPOSITE DESCRIPTIONS OF EXPERIENCE}

Our starting point is phenomenal data that has been subjected to some form of analysis, whether it be tailored made for experiential reports $[46,47]$ or qualitative data in general [35, 48]. Importantly, we do not set out to validate named categories as established by the qualitative analysis of the phenomenal data. Rather, we present our co-researchers with composite ethnographic descriptions, referring to a style of presentation whereby we do not present any single episode of the phenomenon under investigation, but we combine a number of episodes and abstract them away into a typical and telling description [49]. Kordeš and colleagues [4] report than when investigating the lived experience of meditating, precise descriptions of experience serve as better guidelines than straight-out instructions.

The principal investigator presents these composite descriptions as well as a detailed research design during an introductory lecture. The purpose of this lecture is to inform the coresearchers of all the aspects of the study, as well as to explicitly let them know that there is nothing that is being hidden from them. We find this position of empowerment crucial so as to minimize the influence of demand characteristics [50] on their reports. Specifically, we do not wish for them to attempt to guess what the goal of the research is [51]. Rather, we explicitly inform them about the research goal, and then challenge them to attempt to challenge our categories. This challenge is both stated during the introductory lecture and made a part of the process of going through experiential categories later on. ${ }^{6}$

It is important that the overall arc of the workshop is clear to the co-researchers. As one coresearcher reports:

Because we were mostly talking, I feel that everything was left hanging in the air. We never reached any clear conclusions. We could write down different ways in which others experienced things and then through conversation see which experiences overlap or are related to each other. (VR.WM.II-14)

The experience of discussions floating in the middle of nowhere was shared by many coresearchers, in particular those who were involved in longer sessions. We suggest that ahead of the validation session, the co-researchers be given all the composite descriptions with room allocated for notes and eventual names. This allows them to make notes on aspects of experience not currently under investigation, as well as give them a sense of completion.

\section{REACQUANTING THE CO-RESEARCHERS WITH THE EXPERIENCE UNDER INVESTIGATION}


Once we make the aim of the study known, we invite the co-researchers to reacquaint themselves with the experience under investigation. If this experience can be easily induced (e.g., by means of a psychological task), each co-researcher is given privacy to once again observe their experience (i.e., we provoke it) [3,46]. If, on the other hand, the experience cannot be reproduced, the co-researchers are given time to consult their journals. Importantly, reacquainting with the experience should be done in a setting that reflects the social context of the original investigation, as was reported by one of our co-researchers:

We shouldn't do the task together during the group session (with people watching what you're doing) because this aspect changed my experience quite a lot and was pretty distracting. I felt less secure about my report than when I did the task on my own during the [original sessions], and my experience was quite a bit different back then. (VR.WM.II-11)

\section{JOINT INVESTIGATION OF EXPERIENCE UNDER INVESTIGATION}

Then, the co-researchers interview a single individual on her experience. We continue with this process until every co-researcher has been in the role of the reporting on their experience. Meanwhile, the co-researchers are invited to again observe their experience or to read up on their notes. They are prompted to observe specific qualities of their experience:

[1] Is the experience under investigation necessarily such as it was observed during the qualitative analysis or can it be modulated with specific mental gestures?

[2] Can you observe specific differences between two closely related experiential categories?

Theoretically, observing whether a specific aspect of experience is necessarily structure in such a way as observed during the acquisition of phenomenal data or if it can differ in some respect in line with process-oriented constructivism (see section 5). Namely, we are trying to establish a framework that is contingent (i.e., there are potentially infinite possible ways of dividing the categories), and simultaneously internally consistent. In this case, an example of an internal inconsistency would be two categories that would describe the same aspect of one's experience. Further, a similar approach was adopted by Husserl [31; p. 220, emphasis in the original]:

Since every negatum and affirmatum is itself an Object posited as existent, it can, like everything intended to as having a mode of being, become affirmed or denied. In consequence of the constitution of something as existent effected anew at every step, an ideally infinite chain of reiterated modifications therefore results.

Or, on Andrea Staiti's [52; p. 815] paraphrase: "Higher-order affirmation or negation occurs when we set out to revisit a foregoing simple judgment in order to confirm or disconfirm the veridicality of its proposed state of affairs." In explanation, we check whether the structure of a specific aspect of experience - as observed in the acquisition of phenomenal data (whether it be through philosophical intuition or second-person methods) - reflects the lived experience of our individuals, we attempt to provoke experiences that either conform to or deviate from it. During the joint phenomenological interview, our goal is to contrast different experiences of the same phenomenon, trying to ascertain which aspects of experience necessarily remain the same across individual co-researchers, and which aspects may vary. These variations in experience need not be explicit. As the following co-researcher reports, just witnessing how other people experience the same experimental setting, may prompt them to observe their own experience differently: 
My experience changed in that I started to pay attention to new aspects of experience that were described by the others but that I wasn't aware of before. I tried to check if I had a similar experience as them, that I just hadn't realized before, or if these aspects were completely absent to me. But actually, I don't think that my experience changed by that but rather the awareness of my experiences. (VR.WM.II-11)

We will now demonstrate two examples of the attempt at challenging categories induced during the analysis. The first is an example of consensual validation leading to eliminating the category experimental orientation - how it feels to be a participant in a psychological experiment. Importantly, during the actual study, we gathered a number of reports on how one's experience changes when participating in an experiment:

VR.WM.II-S07: Certainly, [being in an experiment] feels different. It can't be compared to anything experienced outside of this setting. So, trying to think of the things I do inside of this setting, of the skills you need to memorize it, whether it's committing a poem to memory, it's different, because you are not trying to compare yourself to others. And then also, sort of the complete setup, of somebody watching you. It wasn't that I was thinking I have to prove myself, I have to solve 75 of them, but it certainly alters how you engage with it. And also what you perceive and notice. (VR.WM.II-PSS-01)

VR.WM.II-09: I just noticed another really important dimension about how it feels to be me in an experiment. It's this dimension of how much you are trying to understand the task itself behind everything. So, going through one pattern, and another pattern, it is one thing. But I often simultaneously try to understand how the task itself works. I mentioned that in our Interview. I noticed that it always starts with four squares, and every time you get two of them correct, the number increases by one. And in this way, you can predict how many black squares in total will appear in the next square, and I was using this knowledge to check if I have all of them. I counted them and I knew how many of them there had to be. (VR.WM.II-PSS-02)

The consensual validation revealed that we may break this experience down into its various social dimensions and being goal-oriented. While these two aspects of experience are prevalent when somebody is undergoing an experimental situation, they are not unique to it. Consider the following example:

VR.WM.II-S07: It sometimes feels in a museum that I have this divide-and-conquer feeling. How I look at the image and parts of the image, and I try to understand what it shows, what it means. That can be very prominent as a strategy that unfolds itself. So, sometimes going to the museum can be quite exhausting for me and sometimes it doesn't feel like I am going there to enjoy the paintings but that I am going there to look and understand. That sort of creates this task-mentality. (VR.WM.II-PSS-01)

While the experience of solving a visual-spatial working memory task was a unique experience within the context of this study, the experience of participating in a study was not. This led us to abandon it as an experiential category.

For our second example, we look at how we constructed a new category during validation sessions. During the qualitative analysis of the data, we induced two categories related to association. The first was an experience in which a to-be-remembered stimulus is accompanied by a visual feeling of something that it resembles. This visual feeling appears as a mental image that is either projected in the outside world, or exists in an internal mental 
space. The second was an experience in which a to-be-remembered stimulus is accompanied by a clear idea of what it resembles. This idea may be explicitly articulated in an inner voice.

We may demonstrate this with a picturesque example observed in the study. A co-researcher was reminded of the swastika by the to-be-remembered stimulus. As we will demonstrate the differences between the established categories visually, we will replace the swastika with the symbol of the fictional state of Tomania from the film The Great Dictator [53]. In the coresearcher's experience, this association was accompanied by mental imagery. Ultimately, this aspect of experience was named "visual image."

Another co-researcher experienced a sense of the to-be-remembered stimulus being like something that might be used as a symbol in a totalitarian regime. As he noticed that this configuration of black-and-white squares was fairly common, he ascribed the meaning of totalitarian iconography to it. This aspect of experience was ultimately named "symbolized description." These two aspects of experience are depicted in Figure 3 as a) and b).

During the validation session, however, we concluded that visual image corresponds to two aspects of experience: one that is comprised by the experience of imagery, and the other comprised of various existential feelings [54]. Thus, we introduced a new category, "atmospheric image." In Figure 3, the new categories are depicted under headings c) and d). Such a refinement and removal of categories is the central goal of the joint interview: we wish to find aspects of experience that are stable and understandable across co-researchers.

a) Visual image

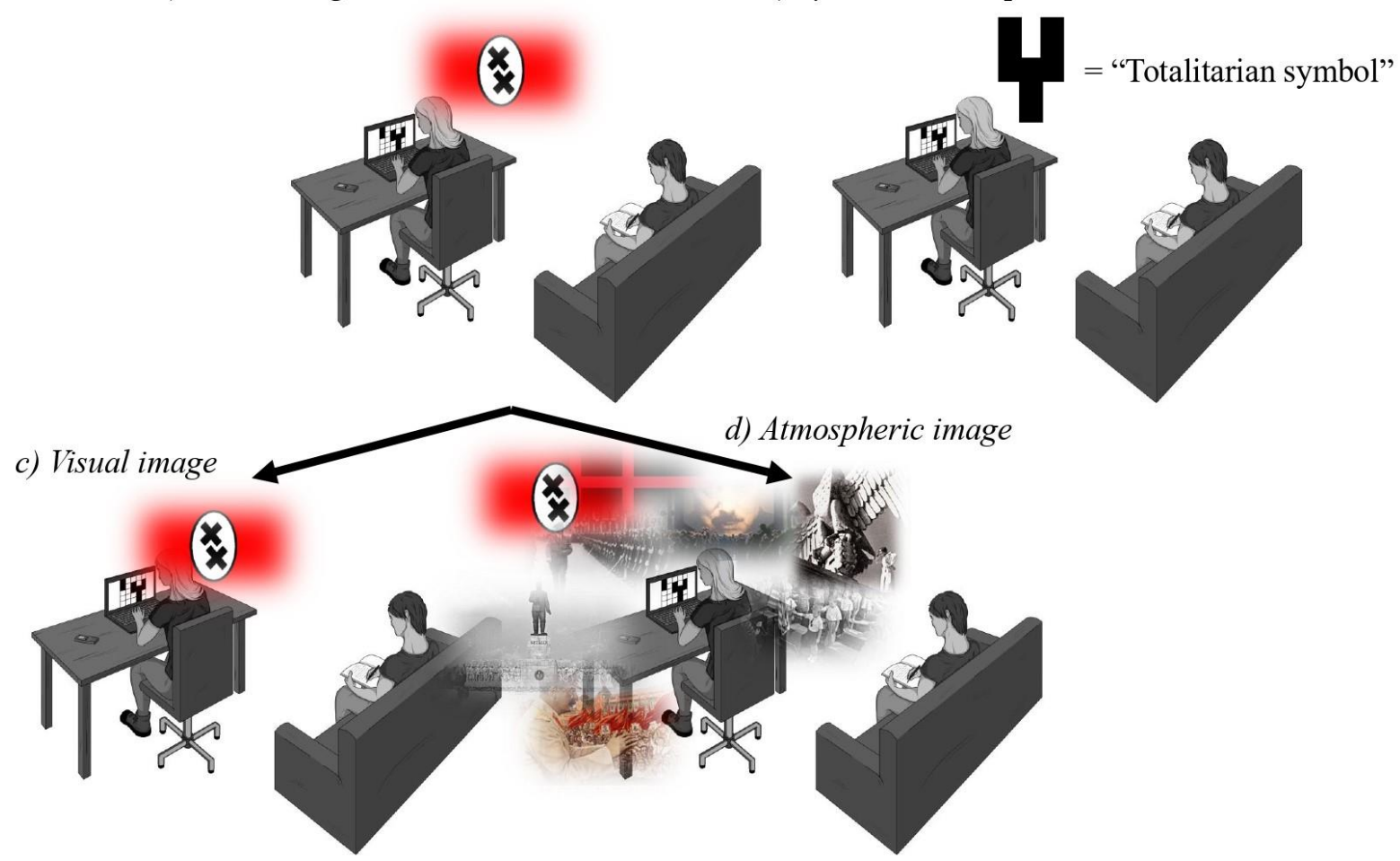

Figure 3: Categories associated with association.

NOMINALIZING EXPERIENTIAL WORLDS 
After performing interviews with each co-researcher, we collectively decide on how to name a specific aspect of experience. For example, consider the following exchange:

VR.WM.II-11: The only thing that feels forced to me is to put competitiveness between me and other people, and against myself on the same axis. I don't know.

PI: Would you say that these are two different things?

VR.WM.II-11: Yeah, it's a very different feeling.

$[\ldots]$

VR.WM.II-10: Exactly! There's an element of jealousy when it's competitiveness with other people.

VR.WM.II-11: Yes! Yes!

Nicole: There's this element that you want to be better than other people.

VR.WM.II-09 Yeah, competitiveness with me is something that I never experienced as negative. It was more encouraging. So, yeah, I would call it ambition. (VR.WM.IIPSS-02)

It is important that each individual is comfortable with the names, and any concerns regarding the vocabulary should be addressed. The final step in the process of validation is for co-researchers to once more be exposed to the experience under investigation, either by provoking it or by consulting their journals. We ask the co-researchers to report on their experience in terms of the vocabulary developed during the workshop. In this step, the coresearchers must be able to discuss their experience with one another with our vocabulary (as per participatory sense-making, the interaction must not break down). Being able to organically use the vocabulary constitutes the most important criterion for an intersubjectively accessible vocabulary on experience.

Once the co-researchers are comfortable with using the intersubjectively developed vocabulary, we hold that our phenomenal data has been consensually validated. Further, we believe that if our co-researchers autonomously developed the vocabulary with which to describe their experience, we can now operationalize these aspects of their experience, i.e., we can make them measurable by introducing them as experimental variables [55]. One obvious type of research design with which our method of validating phenomenal data is compatible is front-loaded phenomenology. According to this approach, we first familiarize ourselves with our object of inquiry, i.e., the experience under investigation, and then - when our co-researchers are equipped with specific categories regarding their experience, they can report on it within the context of a neurophenomenological study [8,56,57]. As Shaun Gallagher [58; p. 38] writes:

To front-load phenomenology does not mean to presuppose or automatically accept the phenomenological results obtained by others. Rather it involves testing those results and more generally a dialectical movement between previous insights gained in phenomenology and preliminary trials that will specify or extend these insights for purposes of the particular experiment or empirical investigation.

This allows us to constrain [7] phenomenal data with behavioral data [59, 60], neuroimaging data [61, 62] electroencephalographic recordings [63], etc.

Importantly, however, our nominalization of experience can be treated as operationalizable only within a given study. For example, we have not observed atmospheric image as such, but atmospheric image as constructed within a study on the experience of solving a visual 
span task [15]. The following section will elaborate on the epistemic value of categories constructed with our method of validation.

\section{THE EPISTEMIC STATUS OF CONSENSUALLY VALIDATED PHENOMENAL DATA}

In the previous section, we laid out our proposed method of consensually validating phenomenal data. Importantly, our approach hinges on a group of co-researchers observing their experience, comparing said experience to composite descriptions of similar experience, and then jointly constructing a vocabulary with which to describe them.

Our method of consensual validation operates under the constructivist epistemology. Constructivism claims that knowledge is not uncovered in an observer-independent world, but rather that it is constructed by the researchers $[64 ; 65]$. In relation to consensual validation, this means that we as co-researchers do not agree on what objectively exists in our experience, but rather that we collectively create a contingent body of knowledge about our experience. It is not knowledge about experience as is, but experience as constructed in a given study [35]. We can specify our epistemology further: we follow constructivist epistemology augmented by process-oriented ontology [66], developed by Alfred North Whitehead. In Process and Reality, Whitehead [67, p. 67) writes:

Actual entities atomize the extensive continuum. This continuum is in itself merely the potentiality for division; an actual entity effects this division. The objectification of the contemporary world merely expresses that world in terms of its potentiality for subdivision and in terms of the mutual perspectives which any such subdivision will bring into real effectiveness.

In explanation, the processes that constitute the world can be divided in any number of ways. How we divide the world, however, is entirely open-ended. The potentiality of the world, therefore may contain contradictions, but once we make it concrete and discrete, the world is divided into an internally coherent system. This potentiality could consistently be observed in our study as the frameworks of experiential categories that we constructed did not apply in their entirety for all of our co-reseachers. What applied to an individual co-researchers was some subset of this framework. Consider the following report on the validation session:

We found multiple common languages. Or rather, I feel that we reached two or three common ways of experiencing the task, and mostly each person could identify themselves with (at least) one way. (VR.WM.II-14)

The end result of our approach is not the construction of the language for describing experience, but the construction of $a$ language. In the following quote from a co-researcher, we can see that this language is approximately precise, which means that it is both adequate for the description of our experience, while it simultaneously remains possible to articulate it in a slightly different way:

Sometimes I felt just a tiny little bit forced to fit my experiences into given categories and dimensions because I thought it would reduce them a bit too much. On the other hand, they did fit into the suggested categories overall, and I imagine that some sort of reduction might be necessary to find common patterns or reach common grounds. It's a bit as if you would measure many people's heights and some would be $1.745 \mathrm{~m}$ and some would be $1.748 \mathrm{~m}$ and you put them both into the category of being $1.74 \mathrm{~m}$. It's some sort of reduction of data, but I don't think that these $0.003 \mathrm{~m}$ make that much of a difference in our world. (VR.WM.II-11) 


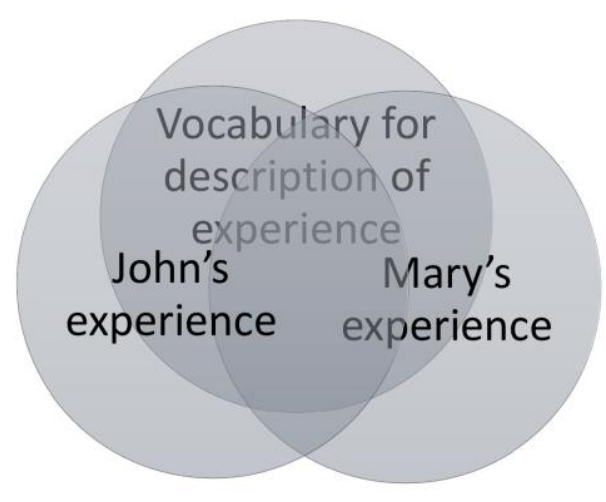

Figure 4: Schematic depiction of fitting our vocabulary to experience

This idea of our method yielding more than one vocabulary for the description of experience is illustrated in the Figure 4. Imagine that we have established a vocabulary to describe the experience of two co-researchers, John and Mary. We may claim that John and Mary's experiences only partially overlap. Their respective experiences approximately map onto the established vocabulary. We can see that there are lacunae both in how adequate our vocabulary is in describing John and Mary's experience as well as in how many aspects of experience are shared between John and Mary. Therefore our vocabulary is necessarily only approximately accurate in describing our co-researchers' experience.

To understand what this idea of potentiality means for the scientific study of experience, we have to defer to Schmidt. He introduces the idea of positings, the assumptions that inform (and by extension construct) our experiential world. "Whatever we do," writes Schmidt [66; p. 43], "we do in the Gestalt of a positing: we do this, and not something else, although we could have done that." These positngs are ways of constructing our experiential worlds. We attain positings both through our previous experience as well as through the culture that we are immersed in. Our experiential world therefore consists of what we expect it to consist of based on our prior experience. It is contingent - but it is not arbitrary.

One of the most important ways in which reality is constrained (and therefore made nonarbitrary) is through the social dimension. As Schmidt writes:

The coupling of process results and their attribution as "real for..." must be socially accepted and thus intersubjectively confirmed, i.e., without the others there is neither certainly nor uncertainly for us. This means that experiencing something as real presupposes the context of acting and communicating communities determined by their framework of interactive dependencies [...] We necessarily live out our liveworlds together with other people. [66; p. 4]

In the scientific study of experience, we are "measuring" precisely observer-dependent worlds, as the observers are the only experts in their experience, as well as the only instrument of measurement through which their experience can be made accessible. If we as a community - "deem real is real in its consequence [66; p. 6]" at least to the extent as it appears to us in our experience, we can add another goal to the process of consensual validation. Not only do we check whether our qualitative analysis of the data was consistent with our co-researchers' experiences, but we can also jointly establish what the meaningful experiential qualities are and thereby solidify them in their experience. We observed exactly such a phenomenon in our study: 
PI: Would you say that this category that I just suggested to you matches your experience, this sense of impression?

VM.WM.II-06: If I look at the screen now, I can see it. I can experience this raw feeling. I can experience it if you give it to me, but before that, no. There's nothing there before that. (VR.WM.II-06-01)

The experience may have always been there (perhaps as an element of pre-reflective consciousness, [69]) or we may have elicited it in her through suggestion [69]. Whatever may be the case, now that the experiencer has access to a word with which to describe it, that aspect of her experience appears more salient to her.
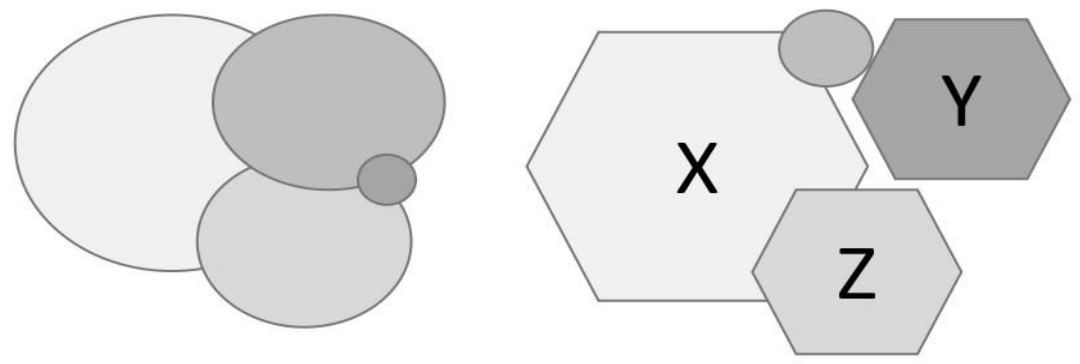

Figure 5: Mary's experience before (left) and after (right) consensual validation.

Let us again defer to the hypothetical case of John and Mary's experience. During the moment Mary actually lived her experience she was more or less aware of the aspects of her experience seen in light-to-mid gray. She paid little attention to the dark gray aspect of her experience. It still constituted how it was to be Mary in that moment, however, she did not bring it to the forefront of her awareness. Then, we conduct consensual validation, establishing the language with which to describe experience consisting of elements $\{X, Y$, Z\}. Not only have we know divided Mary's continuous field of experience into defined elements, we have also made them more salient in her awareness. The dark gray element, now namable as $\mathrm{Y}$, has become more prevalent in her experience. On the other hand, we failed to name the mid-gray element, which is not encompassed in our language. As Mary is now more poised to observe $\mathrm{X}, \mathrm{Y}, \mathrm{Z}$, the salience of the mid-gray element has been reduced.

To reiterate, the epistemic value of the phenomenal data constructed through the proposed method of consensual validation relates to constructivist epistemology in two ways. Firstly, because the continuous flow of our experience can be divided and categorized in ways that are contingent, i.e., can vary across different individuals describing a similar aspect of their experience, we are not establishing the only framework with which to describe a particular aspect of our experience, but merely one of the possible frameworks. Secondly, the framework of experiential categories that we set-up during the participatory sense-making session then works to constrain our co-researchers' experience in the future.

\section{CONCLUSION}

We have offered a method of consensually validating phenomenal data. We constructed our method based on similarities between phenomenology and other descriptive sciences, exemplified by $18^{\text {th }}$ century natural history. While phenomenology and natural history both constitute descriptive sciences, whereby their task is to observe, describe, and classify phenomena under investigation, there are some major differences between them. The foremost difference between the two disciplines is that natural history relies on visual epistemology and exegesis of texts. Neither of these approaches is tenable within 
phenomenology. An important commonality between the disciplines, however, is the importance of intuitive, expert observation. As natural history divides the ways of observing the world into the spectacular and the scientific view, so does phenomenology divide its observation into the natural attitude and bracketing thereof. While these two reductions do not map one onto the other, they still attest to the intuitive way knowledge is given to observers. Based on this kinship, we argue that much like the nominalization of the visual world led to an intersubjectively observable body of scientific knowledge in natural history, nominalization of experiential world may lead to intersubjectively accessible phenomenal data.

We suggest that the nominalization of the experiential world should be done by an autonomous group of co-researchers, rather than being imposed by the principal investigator and checked against the experience of the co-researchers. We derived the importance of autonomous construction of vocabulary both from discussions on the symbol grounding problem, and participatory sense-making. To implement this solution, we iteratively modified the prismatic approach, a method of gathering data on social dynamics. Based on reports on experience of consensual validation, we modified our method.

The final iteration of our approach consists of a group of co-researchers being exposed to composite descriptions of experience. They are invited to once again observe their experience, comparing it to the composite description. They are asked to attempt to falsify the composition descriptions. Finally, co-researchers construct a possible vocabulary for description of experience under investigation. This vocabulary is contingent on a particular research setting, but nonetheless offers a way of operationalizing aspects of experience.

\section{REMARKS}

1. In line with empirical phenomenology, we use the term co-researcher instead of the traditional term participant [44, 70, 71].

2. Nominalism is a philosophically burdened term. As lan Hacking [72; p. 81] writes in The Social Construction of What?, nominalists hold that "[t]he world is so autonomous, so much to itself, that it does not even have what we call structure in itself. We make our puny representations of this world, but all the structure of which we can conceive lies within our representations." Hacking writes on: "The nominalist retorts that we have a good deal to do with organizing what we call a fact. The world of nature does not just come with a totality of facts: rather it is we who organize the world into facts [72; p. 174]." In other words, nominalism does not claim that by naming the world we "cut it at the joint," but rather that we impose structure upon it. As will be seen in section 5 , we are sympathetic to this view, i.e., when we name experience, we do not name it according to the underlying structure of experience. Rather, by naming experience, we impose structure upon it.

3. We use the term phenomenology in a somewhat monolithic sense, disregarding the many different approaches within phenomenology, such as empirical phenomenology [44, 71, 73], philosophical phenomenology [18, 22, 31] and clinical phenomenology [74] to name just a few. While these different schools of thought have different epistemological commitments, we believe that our method may be useful in bringing descriptions of experience to the fore of a community of researchers, regardless of whether the original phenomenal data was obtained through philosophical intuition or various second-person methods.

4. We thank Clémence Compain for help with the French translation. 
5. We do not wish to suggest that this one-directional nature of qualitative research has never been addressed. Indeed, one of the cornerstones of the constructivist grounded theory approach to qualitative analysis is to account the ways in which the researcher constructs rather than discovers knowledge $[35,75,76]$

6. A principled criticism of this explication of phenomena under investigation is that we may induce the experience through suggestion effect. Pete Lush and colleagues [69] have observed that in the general population the rate of suggestibility of individuals is normally distributed; i.e., among highly suggestible individuals, instructions in a research setting may indeed cause them to have the experience presupposed by the research design. While this effect is problematic for empirical research in mind sciences for a number of reasons, we believe that as long as it indeed provokes an experience in our co-researchers rather than merely lead them to say they experienced something, this does not reduce the epistemic value of our phenomenal data.

\section{ACKNOWLEDGMENTS}

I would like to thank and dedicate this paper to Damar Hoogland, without whose support it would never see the light of day.

\section{REFERENCES}

[1] Eisner, E. W.; The Enlightened Eye: Qualitative Inquiry and the Enhancement of Educational Practice. Macmillan, New York, 1991,

[2] Varela, F. J. and Shear, J.; First-person Methodologies: What, Why, How? Journal of Consciousness Studies 6(1), 1-4, 1999,

[3] Petitmengin, C. et al.; What is it like to meditate? Methods and issues for a microphenomenological description of meditative experience. Journal of Consciousness Studies 23(5-6), 170-198, 2017,

[4] Kordeš, U., Oblak, A., Smrdu, M. and Demšar, E.; Ethnography of Meditation: An Account of Pursuing Meditative Practice as a Tool for Researching Consciousness. Journal of Consciousness Studies 26(7-8), 184-237, 2019,

[5] Nosek, B. A. et al.; Promoting an Open Research Culture: Author Guidelines for Journals Could Help to Promote Transparency, Openness, and Reproducibility. Science 348(6242), 1422-1425, 2015 ,

[6] Moravcsik, A.; Transparency: The Revolution in Qualitative Research. PS: Political Science \& Politics 47(1), 48-53, 2014,

[7] Varela, F. J.; Neurophenomenology: A Methodological Remedy for the Hard Problem. Journal of Consciousness Studies 3(4), 330-349, 1996,

[8] Gallagher, S.; Phenomenology and Experimental Design: Toward a Phenomenologically Enlightened Experimental Science. Journal of Consciousness Studies 10(9-10), 85-99, 2003,

[9] Grimaldi, D. A. and Engel, M. S.; Why Descriptive Science Still Matters. BioScience 57(1), 646647, 2007,

[10] Casadevall, A. and Ferric C. F.; Descriptive Science. Infection \& Immunity 76(9), 3835-3836, 2008 ,

[11] Haeckel, E. H. P. A.; Kunstformen der Natur. Bibliographisches Institut, Vienna, 1904,

[12] van Loon, F. W.; Planisphaeri Celeste. Wikimedia Commons, retrieved on $26^{\text {th }}$ December 2019 from

https://upload.wikimedia.org/wikipedia/commons/7/75/Planisph\%C3\%A6ri_c\%C5\%93leste.jpg, 
[13] Dupré, J.; In Defense of Classification. Studies in History and Philosophy of Biological and Biomedical Sciences 32(2), 203-2019, 2001,

[14] Dupré, J.; A Process Ontology for Biology. Physiology News 100(1), 33-34, 2015,

[15] Yarkoni, A.; The Generalizability Crisis. PsyArXiv. https://doi.org/10.31234/osf.io/jqw35,

[16] Foucault, M.; The Order of Things: An Archeology of the Human Scieneces. Routledge, London, 2002 ,

[17] Linnaeus, C.; Systema naturae per regna tria naturae: secundum classes, ordines, genera, species cum characteribus et differentiis. Retrieved on $26^{\text {th }}$ December 2019 from http://www2.linnaeus.uu.se/online/animal/1_1.html,

[18] Sartre, J.; The Imaginary: A Phenomenological Psychology of the Imagination. Routledge, New York, 2010,

[19] Ricoeur, P.; Phenomenology and Hermeneutics. Noûs 9(1), 85-102, 1975,

[20] Giorgi, A.; The Descriptive Phenomenological Method in Psychology. Duquesne University Press, Pittsburgh, 2009,

[21] Husserl, E.; On the Phenomenology of Consciousness of Internal Time (1893 - 1917). Kluwer Academic Publishing, Dordrecht, 1991,

[22] Merleu-Ponty, M.; Phenomenology of Perception. Routledge, London, 2012,

[23] Varela, F. J.; The Specious Present: A Neurophenomenology of Time Consciousness. In Petitot, J., Varela F. J., Pachoud, B. and Roy J., eds.: Naturalizing Phenomenology: Issues in Contemporary Phenomenology and Cognitive Science. MIT Press, Cambridge, 1999,

[24] Bleichmar, D.; The Visible Empire: Botanical Expeditions and Visual Culture in the Hispanic Enlightenment. The University of Chicago Press, Chicago, 2012,

[25] Derrida, J.; Of Grammatology. Johns Hopkins University Press, Baltimore, 1998,

[26] Husserl, E.; Thing and Space: Lectures of 1907. Kluwer Academic Publishings, Dordrecht, 1997,

[27] Varela, F. J., Thomspon, E. and Rosch, E.; The Embodied Mind: Cognitive Science and Human Experience. MIT Press, Cambridge, 2017,

[28] Flanagan, O. J.; Consciousness Reconsidered. MIT Press, Cambridge, 1992,

[29] Roy et al.; Beyond the Gap: An Introduction to Naturalizing Phenomenology. In Petitot, J., Varela F. J., Pachoud, B. and Roy J., eds.: Naturalizing Phenomenology: Issues in Contemporary Phenomenology and Cognitive Science. MIT Press, Cambridge, 1999,

[30] Thompson, E.; Mind in Life: Biology, Phenomenology, and the Sciences of the Mind. Harvard University Press, Cambridge, 2007,

[31] Husserl, E.; Ideas Pertaining to a Pure Phenomenology and to a Phenomenological Philosophy. Martinus Nijhoff Publishing, The Hague, 1983,

[32] Fink, E. The Phenomenological Philosophy of Edmund Husserl and Contemporary Criticism. In Elveton R. O., ed.: The Phenomenology of Husserl: Selected Critical Readings. Quadrangle Books, Chicago, 1970,

[33] Husserl, E. Idées directrices pour une phénoménologie. Gallimard, Paris, 1950,

[34] Klüver, H.; Mescal and the Mechanisms of Hallucination. The University of Chicago Press, Chicago, 1966,

[35] Charmaz, K.; Constructing Grounded Theory: A Practical Guide Through Qualitative Analysis. Sage Publications, London, 2004,

[36] Steels, L.; The Symbol Grounding Problem Has Been Solved. So What's Next? In de Vega, M., Glenberg, A. and Graesser, A., eds. Symbols and Embodiment: Debates on Meaning and Cognition. Oxford University Press, Oxford, 2008,

[37] Harnad, S. The Symbol Grounding Problem. Physica 42(1), 335-346, 1999

[38] De Jaegher, H.; Intersubjectivity in the Study of Experience. Constructivist Foundations 14(2), 393-395, 2016 
[39] Solomonova, E. and Wei, S. X.; Exploring the Depth of Dream Experience: The Enactive Framework and Methods for Neurophenomenological Research. Constructivist Foundations 11(2), 407-442, 2014,

[40] De Jaegher, H. and Di Paolo, E.; Participatory Sense-making. Phenomenology and the Cognitive Sciences 6(4), 485-507, 2007,

[41] Cuffari, E., De Jaegher, H. and Di Paolo, E.; From Participatory Sense-making to Language: There and Back Again. Phenomenology and the Cognitive Sciences 14(4), 1089-1125, 2015,

[42] Pieper, D. and Clénin, D.; Verkörperte Selbst- und Fremdwahrnehmung sozialen Handelns. Eine praktisch-theoretische Forschungsperspektive. In Boehle, F. and Weihrich, M., eds. Die Körperlichkeit sozialen Handelns. Soziale Ordnung jenseits von Normen und Institutionen. Transcript, Bielefeld, 2010,

[43] Demšar, E.; The circular character of the conceptual space of cognitive science : between scientific and lived realities of the mind. MSc thesis, 2017,

[44] Hurlburt, R. T.; Investigating Pristine Inner Experience: Moments of Truth. Cambridge University Press, Cambridge, 2010,

[45] Repovš, G. and Baddeley, A. D.; The multi-component model of working memory: Explorations in experimental cognitive psychology. Neuroscience 139(1), 5-21, 2006,

[46] Petitmengin C., Remillieux A. and Valenzuela-Moguillansky C.; Discovering the Structures of Lived Experience: Towards a Micro-phenomenological Analysis Method. Phenomenology and the Cognitive Sciences 18(4), 691-730, 2018,

[47] Valenzuela-Moguillansky C. and Vásquez-Rosati A.; An analysis procedure for the microphenomenological interview. Constructivist Foundations 14(2), 123-145, 2019,

[48] Flick, U.; An Introduction to Qualitative Research. Sage, London, 2009,

[49] Murchinson, J. M.; Ethnography Essentials: Designing, Conducting, and Presenting your Research. Jossey-Bass, San Francisco, 2010,

[50] Orne, M.; On the Social Psychology of the Psychological Experiment: With Particular Reference to Demand Characteristics and their Implications. American Psychologist 17(11), 776-783, 1962 ,

[51] Nichols A. L. \& Manner J. K.; The Good Subject Effect: Investigating Participant Demand Characteristics. The Journal of General Psychology 135(2), 151-166, 2008,

[52] Staiti, A.; Husserl and Rickert on the Nature of Judgment. Philosophy Compass 10(12), 815-827, 2015 ,

[53] Chaplin, C. The Great Dictator. The Charles Chaplin Film Corporation, USA, 1940,

[54] Ratcliff, C.; The Phenomenology of Existential Feelings. In Fingerhut, J. and Marienberg, S., eds. Feelings of Being Alive / Gefühle des Lebendigseins. De Gruyter, Berlin, 2008,

[55] Bridgman, P. W.; The Logic of Modern Physics. Macmillan, New York, 1958,

[56] Gallagher, S. and Brøsted Sørensen, J.; Experimenting with Phenomenology. Consciousness and Cognition 15(1), 119-134, 2006,

[57] Zahavi, D.; Naturalized Phenomenology. In Gallagher, S. and Schmicking, D., eds. Handbook of Phenomenology and Cognitive Science. Springer Science + Business Media, Berlin, 2010,

[58] Gallagher, S.; Phenomenology. Macmillan, New York, 2012,

[59] Oblak, A. and Kordeš, U.; Neurophenomenology: An Ontological Remedy for the Hard Problem? Constructivist Foundations 14(1), 59-61, 2018,

[60] Kordeš, U.; Horizons of Analysis 14(2), 149-152, 2019,

[61] Tsakiris, M., Longo, M. R. and Haggard, P.; Having a body versus moving your body: Neural signatures of agency and body-ownership. Neuropsychologia 48(9), 2740-2749, 2010,

[62] Belzeaux, R., Cermolacce, M. and Jadri, R.; Hallucinations: Toward a Dialogue between Phenomenology and Brain Research. Journal of Consciousness Studies 23(7-8), 144-162, 2016, 
[63] Lutz, A., Lachaux, J., Martinerie, J. and Varela, F. J.; Guiding the study of brain dynamics by using first-person data: Synchrony patterns correlate with ongoing conscious states during a simple visual task. PNAS 99(3), 1586-1591, 2002,

[64] von Glasersfeld, E.; Radical Constructivism: A Way of Learning. Routledge, London, 1995,

[65] Riegler, A.; Towards a Radical Constructvist Understanding of Science. Foundations of Science 6(1), 1-30, 2001,

[66] Schmidt, S. J.; From Objects to Processes: A Proposal to Rewrite Radical Constructivism. Constructivist Foundations 7(1), 1-9, 2011,

[67] Whitehead, A. N.; Process and Reality: An Essay in Cosmology. The Free Press, New York, 1978,

[68] Froese T. and Fuchs T.; The Extended Body: A Case Study in the Neurophenomenology of Social Interaction. Phenomenology and the Cognitive Science 11(1), 205-235, 2012,

[69] Lush, P., Botan, V., Scott, R., Seth, A., Ward, J. and Dienes, Z.; Phenomenological control: response to imaginative suggestion predicts measures of mirror touch synaesthesia, vicarious pain and the rubber hand illusion. PsyArXiv, 16 Apr. 2019. Web,

[70] Lah A. and Kordeš U.; One Cannot “Just Ask” About Experience. In: Markič O., Strle T., Kordeš U. \& Gams M., eds. Kognitivna znanost/Cognitive Sciences. Proceedings of the 17th international multiconference "Information Society - IS 2014.” Volume C. Inštitut Jožef Štefan, Ljubljana, 2014,

[71] Kordeš U.; Going Beyond Theory: Constructivism and Empirical Phenomenology. Constructivist Foundations 11(2), 375-385, 2016,

[72] Hacking, I.; The Social Construction of What? Harvard University Press, Cambridge, 1999,

[73] Petitmengin C.; Describing One's Subjective Experience in the Second Person: An Interview Method for the Science of Consciousness. Phenomenology and the Cognitive Sciences 5(1), 229-269, 2006,

[74] Fuchs, T., Embodiment and Psychopathology: A Phenomenological Perspective. Current Opinions in Psychiatry 22(6), 570-575, 2009,

[75] Mills, J., Bonner, A. and Francis, K.; The Development of Constructivist Grounded Theory. International Journal of Qualitative Methods 5(1), 25-35, 2006,

[76] Mills, J., Bonner, A. and Francis, K. Adopting a Constructivist Approach to Grounded Theory: Implications for Research Design. International Journal of Nursing Practice 12(1), 8-13, 2006, 